\title{
Gastroscopy following a positive fecal occult blood test and negative colonoscopy: Systematic review and guideline
}

\author{
Johane Allard MD FRCP ${ }^{1}$, Roxanne Cosby MA², M Elisabeth Del Giudice MSc MD CCFP ${ }^{3}$, \\ E Jan Irvine MD FRCPC MSc ${ }^{4}$, David Morgan MD MSc FRCPC ${ }^{5}$, Jill Tinmouth MD PhD FRCPC
}

\begin{abstract}
J Allard, R Cosby, ME Del Giudice, EJ Irvine, D Morgan, J Tinmouth. Gastroscopy following a positive fecal occult blood test and negative colonoscopy: Systematic review and guideline. Can J Gastroenterol 2010;24(2):113-120.
\end{abstract}

BACKGROUND: A sizeable number of individuals who participate in population-based colorectal cancer (CRC) screening programs and have a positive fecal occult blood test (FOBT) do not have an identifiable lesion found at colonoscopy to account for their positive FOBT screen.

OBJECTIVE: To evaluate the evidence and provide recommendations regarding the use of routine esophagogastroduodenoscopy (EGD) to detect upper gastrointestinal (UGI) cancers in patients participating in a population-based CRC screening program who are FOBT positive and colonoscopy negative.

METHODS: A systematic review was used to develop the evidentiary base and to inform the evidence-based recommendations provided.

RESULTS: Nine studies identified a group of patients who were FOBT positive and colonoscopy negative. Three studies found no cases of UGI cancer. Four studies reported cases of UGI cancer; three found UGI cancer in $1 \%$ or less of the population studied, and one study found one case of UGI cancer that represented 7\% of their small subgroup of FOBT-positive/colonoscopy-negative patients. Two studies did not provide outcome information that could be specifically related to the FOBT-positive/colonoscopy-negative subgroup.

CONCLUSION: The current body of evidence is insufficient to recommend for or against routine EGD as a means of detecting gastric or esophageal cancers for patients who are FOBT positive/colonoscopy negative, in a population-based CRC screening program. The decision to perform EGD should be individualized and based on clinical judgement.

Key Words: Colonoscopy; Esophagogastroduodenoscopy; Fecal occult blood test; Mass screening; Systematic review; Upper gastrointestinal cancer
La gastroscopie après une recherche positive de sang occulte dans les selles et une coloscopie négative : Une analyse systématique et des lignes directrices

HISTORIQUE : Bien des gens qui participent à un programme de dépistage du cancer colorectal (CCR) en population et obtiennent un résultat de recherche de sang occulte dans les selles (RSOS) positif n'ont pas de lésion identifiable à la coloscopie pour justifier ce dépistage positif. OBJECTIF : Évaluer les données probantes et fournir des recommandations au sujet du recours systématique à l'œsophagogastroduodénoscopie (OGD) pour déceler des cancers du transit oesogastroduodénal (TOGD) chez des patients qui participent à un programme de dépistage du CCR positif à une RSOS et négatif à la coloscopie.

MÉTHODOLOGIE : Une analyse systématique a permis d'établir une base de données probantes et d'étayer les recommandations probantes fournies.

RÉSULTATS : Neuf études portaient sur un groupe de patients positifs à une RSOS et négatifs à une coloscopie. Trois études n'ont dépisté aucun cas de cancer du TOGD. Quatre études en ont déclaré des cas : trois ont décelé l'un de ces cancers chez $1 \%$ ou moins de la population à l'étude et une en a découvert un cas, qui représentait $7 \%$ du petit sous-groupe de patients positifs à la RSOS et négatifs à la coloscopie. Deux études ne contenaient pas d'information d'issues susceptible d'être reliée spécifiquement au sous-groupe positif à la RSOS et négatif à la coloscopie.

CONCLUSION : L'ensemble de données probantes actuel ne suffit pas pour recommander une OGD systématique afin de déceler les cancers gastriques ou œsophagiens chez les patients positifs à la RSOS et négatifs à la coloscopie dans le cadre d'un programme de dépistage du CCR en population. La décision d'exécuter une OGD doit être personnalisée et se fonder sur le jugement clinique.
Tn Canada, colorectal cancer (CRC) is the fourth most commonly diagnosed cancer and the second leading cause of cancer death, with an estimated 21,500 new cases and 8900 deaths in 2008. In Ontario, approximately 8000 new cases and 3250 deaths occured in 2008 (1). If CRC is detected early, the five-year survival rate is $93.2 \%$, whereas the five-year survival rate for individuals with metastatic disease is only 8.1\% (2). Most patients with early CRCs are asymptomatic and population screening has been shown to be an effective strategy in significantly reducing mortality rates (3-6). Toward this goal, a CRC screening program, 'ColonCancerCheck' (www.coloncancercheck.ca), was launched in the province of Ontario in 2008. Through this program, average-risk adults, defined as individuals who are asymptomatic, at least 50 years of age and without any first-degree relatives with a history of CRC, are screened with a fecal occult blood test (FOBT). Any individual with a positive FOBT is then referred to a specialist for colonoscopy.

${ }^{1}$ Department of Medicine, Division of Gastroenterology, University of Toronto, University Health Network - Toronto General Hospital, Toronto;

${ }^{2}$ Cancer Care Ontario, Program in Evidence-Based Care and Department of Clinical Epidemiology and Biostatistics, McMaster University,

Hamilton; ${ }^{3}$ Department of Community and Family Medicine, University of Toronto, Sunnybrook Health Sciences Centre, Toronto; ${ }^{4}$ University

of Toronto and Division of Gastroenterology, St Michael's Hospital, Toronto; ${ }^{5}$ Division of Gastroenterology, St Joseph's Healthcare, Hamilton;

${ }^{6}$ Department of Medicine, Division of Gastroenterology, University of Toronto, Sunnybrook Health Sciences Centre, Toronto, Ontario

Correspondence: Dr Johane Allard, Toronto General Hospital, 200 Elizabeth Street, Toronto, Ontario M5G 2C4. Telephone 416-340-4800,

fax 416-348-0065, e-mail johane.allard@uhn.on.ca

Received for publication April 27, 2009. Accepted May 30, 2009 
A large number of individuals with a positive FOBT do not have an identifiable lesion found at colonoscopy to account for their positive FOBT screen (7). Results of a pilot CRC screening program in the United Kingdom (UK) indicated that 1.9\% of those screened for CRC were FOBT positive, and 53\% of these patients screened negative at colonoscopy (8). Therefore, approximately $1 \%$ of those who presented for CRC population screening were FOBT positive and colonoscopy negative in the UK experience. Results from a French CRC screening program (9) reported that $2.6 \%$ of those screened were FOBT positive, of which $37 \%$ were negative at colonoscopy. While some of these cases may be attributable to a false-positive FOBT, some may also be attributable to blood loss from upper gastrointestinal (UGI) or small bowel lesions including, but not limited to, possible malignancies - diagnosis of these lesions require further investigation. Presently, only some FOBT-positive/ colonoscopy-negative patients are referred for UGI investigations and up to $5.9 \%$ of negative colonoscopy investigations may be owing to false-negative test results (10). Currently, there is a lack of consensus regarding whether UGI investigation by esophagogastroduodenoscopy (EGD) is routinely warranted in FOBT-positive/colonoscopy-negative cases. Given the limited endoscopy resources in Ontario and other jurisdictions, it is important to determine whether EGD is appropriate in this clinical context.

The aim of the present systematic review was to evaluate the evidence and provide recommendations concerning the use of routine EGD to detect UGI cancers in men and women participating in a population-based CRC screening program who have had a positive FOBT followed by colonoscopy without identifiable colonic lesions to account for their positive FOBT.

The intended audience for the present guidance document is health professionals, which may include gastroenterologists, family physicians, surgeons and other health care professionals involved in the screening, diagnosis, treatment and follow-up of individuals enrolled in a population-based CRC screening program.

\section{METHODS}

The present guideline, developed by Cancer Care Ontario's (CCO) Program in Evidence-Based Care (PEBC), used the methods of the practice guidelines development cycle (11). The core methodology used to develop the evidentiary base was the systematic review. Evidence was selected by one author who was a methodologist (RC) and reviewed by two other authors (JA and EJI). The reference lists from these sources were also searched for additional trials.

The UGI Screening Working Panel consisted of several gastroenterologists, a family physician, a methodologist and a CCO representative from the CRC screening program.

The present systematic review is a convenient and up-to-date source of the best available evidence examining UGI endoscopic screening subsequent to a positive FOBT and negative colonoscopy. The body of evidence in the review, which forms the basis of the recommendations, is primarily comprised of prospective and retrospective cohort and cross-sectional studies that have evaluated the role of UGI investigation in FOBTpositive/colonoscopy-negative patients. The systematic review and companion recommendations are intended to promote evidence-based practice in Ontario. The PEBC is supported by the Ontario Ministry of Health and Long-Term Care through CCO. All work produced by the PEBC is editorially independent from its funding source.

\section{Literature search strategy}

The MEDLINE (1990 through May [week one] 2008) and EMBASE (1990 through week 20, 2008) databases were searched for relevant publications, using terms pertaining to colonoscopy, gastroscopy and gastrointestinal neoplasms. The reference lists of included studies were also searched. The start year of the search was 1990 because it is when evidence regarding screening began to appear in the literature. The full MEDLINE and EMBASE literature search strategies can be found in Appendixes 1 and 2, respectively.

\section{Environmental scan}

An environmental scan was conducted in May 2008, to locate published and unpublished documents outside the indexed literature. Documents pertaining to UGI screening for patients who were colonoscopy negative following a positive FOBT in a population-based CRC screening program from Canada and health care organizations in the United States, UK, Australia and New Zealand were searched. The complete list of resources used in the search are presented in Appendix 3.

\section{Study selection criteria}

Articles selected for inclusion in the present systematic review were English language reports involving human participants. They included practice guidelines, systematic reviews (with or without meta-analyses), and all publication types that examined the role of UGI screening in patients who had a negative colonoscopy following a positive FOBT. Articles such as letters, editorials, notes, case reports, commentaries and nonsystematic reviews, were excluded.

If an EGD was not performed after a negative colonoscopy and patients were followed to determine a new occurrence of UGI cancer, the studies involved were included only if they reported cases of UGI cancers occurring within three years of the positive FOBT. Three years was chosen based on the mean sojourn time for CRC (the time between an undetectable preclinical screening and the clinical phase), reported to be 2.8 years in a Taiwanese study (12) and 2.6 years in a French study (13).

In theory, population screening should include only asymptomatic participants. However, in practice, some individuals presenting for screening are symptomatic, which realistically reflects medical practice. For this reason, articles relating to either symptomatic or asymptomatic patients were retained. At minimum, a group of FOBT-positive/colonoscopy-negative patients were required to be identified in the article.

\section{Internal and external review}

All documents produced in collaboration with the PEBC undergo rigorous internal review, including a full data audit as well as copyediting by staff not involved in the development of the document. Before submission of the present report (systematic review and companion guideline) to external review, the report was reviewed by an expert panel that consisted of a group of endoscopists from the Clinical Advisory Committee 
of CCO's Colorectal Cancer Screening Program. In addition, the report was reviewed and approved by the PEBC Report Approval Panel, which consists of two members: an expert methodologist and an oncologist with expertise in clinical and methodology issues.

The PEBC external review process is two pronged and includes a targeted peer review that is intended to obtain direct feedback on the draft report from a small number of specified content experts and a professional consultation that is intended to facilitate dissemination of the final guidance report to Ontario practitioners. Following endorsement by the PEBC Report Approval Panel, the present document was sent to four targeted peer reviewers from across Canada considered to be clinical and/or methodological experts on the topic; written comments were invited. Feedback was also obtained through a brief online survey of health care professionals who are the intended users of the guideline, namely, gastroenterologists, family physicians and surgeons. Written comments were invited from this group as well.

\section{RESULTS}

\section{Literature search and environmental scan}

The MEDLINE and EMBASE searches resulted in 1558 hits. A total of nine articles met selection criteria and were retained (7,14-21): five from MEDLINE, three from EMBASE and one from the reference list of included studies. The environmental scan did not yield any papers, documents or guidance pertaining to the use of UGI investigations in patients who were FOBT-positive/colonoscopy-negative.

\section{Study characteristics and quality}

Five studies that examined the occurrence of gastric cancer following a negative colonoscopy in patients who had positive FOBTs were identified $(7,14-17)$. Of these, two $(7,14)$ were studies in which patients were originally part of a population screening program for CRC. Participants in the Thomas and Hardcastle (14) study who were FOBT-positive/colonoscopynegative, and were subsequently noted to be symptomatic, underwent EGD. The outcomes for this small group of patients $(\mathrm{n}=14)$ were reported. Although Zappa et al (7) identified a large group of FOBT-positive/colonoscopy-negative patients who did not undergo EGD, they performed a follow-up using database linkage procedures. Because they reported the number of UGI cancers that occurred within a three-year follow-up period, this study was included in the present report. The remaining three studies (15-17) were prospective (15) and retrospective $(16,17)$, in which all FOBT-positive/colonoscopynegative patients were assessed by EGD for gastric cancer.

Four studies that examined the diagnosis of gastric cancer in patients who had same-day EGD and colonoscopy after a positive FOBT were identified; in these studies, a subgroup of colonoscopy-negative patients could be identified (18-21). Two studies collected data prospectively $(18,21)$, and two studies collected data retrospectively $(19,20)$. Participants in all four studies underwent bidirectional endoscopy. The order of endoscopy was either colonoscopy followed by EGD $(20,21)$, EGD followed by colonoscopy (19) or as determined by institutional availability (18). Because the outcomes related to the subgroup of FOBT-positive/colonoscopy-negative patients were not reported separately in three $(18,19,21)$ of these four studies, only limited information could be obtained from these articles. Table 1 provides a summary of each study.

Five studies used a guaiac FOBT only $(15,16,18,20,21)$, two studies used both a guaiac and an immunochemical FOBT, with patients being tested with a guaiac test until 1995, and with an immunochemical test after 1995 in one study (7), and with one, the other, or both tests in some cases, in the other study $(14)$. Two studies $(17,19)$ did not report the type of FOBT used. Three studies $(14,18,20)$ did not rehydrate samples, while the remaining studies did not indicate whether samples were rehydrated.

Measures of study quality included conflict of interest reporting and the identification of funding sources. Only Hisamuddin et al (20) reported specifically on authors' conflicts of interest and indicated they had no conflicts. No other papers reported on conflicts of interest. Information regarding funding sources was not reported in any of these studies.

\section{Cancer outcomes}

Nine studies identified a group of patients who were FOBTpositive/colonoscopy-negative (Table 2 ). Some studies were limited to patients who were either symptomatic (14) or asymptomatic $(15,17)$, others included both symptomatic and asymptomatic patients $(16,18,20)$, and several studies did not report whether patients were symptomatic $(7,19,21)$. Chen et al (16) categorized their patients into four groups: asymptomatic, symptomatic, severely anemic (which included those who were both symptomatic and severely anemic) and 'incomplete', which was a group of patients with incomplete documentation with respect to anemia and/or symptoms. One study (20) did not provide a definition of 'symptomatic'. In all other studies that included symptomatic patients, symptomatic was defined as including dyspepsia as well a subset of the following: dysphagia, heartburn, abdominal pain, nausea, vomiting, weight loss and diarrhea $(14,16,18)$. One study $(20)$ reported that patients were required to have at least one positive window to be considered FOBT positive. No other studies reported how many windows were required to be positive for a patient to be considered FOBT positive.

Eight of the studies performed EGD on all FOBT-positive/ colonoscopy-negative patients (14-21), whereas one study (7) conducted a large retrospective cohort study of patients who were followed through a cancer registry linkage. Rates of positive findings (not limited to cancers) at EGD ranged from a low of $13 \%$ (19) to a high of $43 \%$ (14). Of note, this latter study is a report of a very small subgroup $(\mathrm{n}=14)$ of symptomatic patients.

Three studies $(15,16,20)$ found no cases of UGI cancer, defined as either gastric or esophageal cancer. Four studies reported cases of UGI cancer. Thomas and Hardcastle (14) found only one case of gastric cancer in their small subgroup of 14 symptomatic FOBT-positive/colonoscopy-negative patients. Bini et al (17) found five cases of UGI cancer (four gastric and one esophageal) in their study of 498 asymptomatic patients, and Zappa et al (7) found 14 cases of gastric cancer in 3555 patients between zero and 35 months following a positive FOBT (unknown if patients were symptomatic or asymptomatic). Zuckerman and Benitez (18) found one case of UGI cancer in their study of 74 asymptomatic and symptomatic FOBT-positive/colonoscopy-negative patients. 
TABLE 1

Summary of studies of fecal occult blood test-positive (FOBT-pos)/colonoscopy-negative (col-neg) patients or studies with an identifiable FOBT-pos/col-neg subgroup of patients

\begin{tabular}{|c|c|c|c|c|c|}
\hline $\begin{array}{l}\text { Author } \\
\text { (reference) }\end{array}$ & Study type & Study details & $\begin{array}{l}\text { Type of } \\
\text { FOBT }\end{array}$ & $\begin{array}{l}\text { Guaiac } \\
\text { sample } \\
\text { hydration } \\
\text { status }\end{array}$ & $\begin{array}{l}\text { FOBT-pos/ } \\
\text { col-neg, } \\
\text { patients, n }\end{array}$ \\
\hline $\begin{array}{l}\text { Thomas and } \\
\text { Hardcastle (14) }\end{array}$ & Prospective & $\begin{array}{l}\text { Asymptomatic patients randomly assigned to colorectal cancer } \\
\text { screening with FOBT or control group (received no screening) } \\
\text { FOBT-pos patients who underwent colonoscopy or flexible } \\
\text { sigmoidoscopy combined with double-contrast barium enema } \\
\text { EGD performed on FOBT-pos/col-neg patients who were } \\
\text { subsequently deemed to be symptomatic }\end{array}$ & $\begin{array}{l}\text { Guaiac and/or } \\
\text { immunochemical }\end{array}$ & $\begin{array}{l}\text { Not } \\
\text { rehydrated }\end{array}$ & 14 \\
\hline $\begin{array}{l}\text { Hsia and al-Kawas } \\
\text { (15) }\end{array}$ & Prospective & $\begin{array}{l}\text { Asymptomatic FOBT-pos/col-neg patients referred for upper } \\
\text { endoscopy }\end{array}$ & Guaiac & Not reported & 70 \\
\hline Chen et al (16) & Retrospective & $\begin{array}{l}\text { FOBT-pos/col-neg patients who were asymptomatic, } \\
\text { symptomatic, anemic or had incomplete documentation and } \\
\text { were referred for upper endoscopy }\end{array}$ & Guaiac & Not reported & 211 \\
\hline Bini et al (17) & Retrospective & $\begin{array}{l}\text { Asymptomatic FOBT-pos/col-neg patients who underwent upper } \\
\text { endoscopy }\end{array}$ & Not reported & Not reported & 498 \\
\hline Zappa et al (7) & Retrospective & $\begin{array}{l}\text { Patients attending FOBT screening identified from a } \\
\text { screening database } \\
\text { FOBT-pos patients underwent colonoscopy } \\
\text { Authors report on a FOBT-pos/col-neg subgroup } \\
\text { EGD not performed but patients followed through databases } \\
\text { and registries } \\
\text { Authors report the number of upper gastrointestinal cancers in } \\
\text { the first } 3 \text { years after a positive FOBT }\end{array}$ & $\begin{array}{l}\text { Guaiac or } \\
\text { immunochemical }\end{array}$ & Not reported & 3555 \\
\hline $\begin{array}{l}\text { Hisamuddin et al } \\
\text { (20) }\end{array}$ & Retrospective & $\begin{array}{l}\text { FOBT-pos patients who underwent same-day bidirectional } \\
\text { endoscopy } \\
\text { Sequence was colonoscopy followed by EGD } \\
\text { Authors report outcomes from an FOBT-pos/col-neg subgroup }\end{array}$ & Guaiac & $\begin{array}{l}\text { Not } \\
\text { rehydrated }\end{array}$ & 70 \\
\hline $\begin{array}{l}\text { Zuckerman and } \\
\text { Benitez (18) }\end{array}$ & Prospective & $\begin{array}{l}\text { FOBT-pos or iron-deficiency anemia patients who underwent } \\
\text { bidirectional endoscopy } \\
\text { Sequence dependent on scheduling and could be separated by } \\
\text { up to } 14 \text { days } \\
\text { Authors identify a group of FOBT-pos/col-neg patients but do not } \\
\text { report separate outcomes for this subgroup }\end{array}$ & Guaiac & $\begin{array}{l}\text { Not } \\
\text { rehydrated }\end{array}$ & 74 \\
\hline Ali et al (19) & Retrospective & $\begin{array}{l}\text { FOBT-pos patients underwent same-day bidirectional endoscopy } \\
\text { Sequence was EGD followed by colonoscopy in } 85 \% \text { of cases } \\
\text { Authors identify a group of FOBT-pos/col-neg patients but do not } \\
\text { report separate outcomes for this subgroup }\end{array}$ & Not reported & Not reported & 125 \\
\hline $\begin{array}{l}\text { Stray and Weberg } \\
(21)\end{array}$ & Prospective & $\begin{array}{l}\text { FOBT-pos patients with or without iron-deficiency anemia, solely } \\
\text { iron-deficiency anemia or solely iron-deficiency and underwent } \\
\text { same-day bidirectional endoscopy } \\
\text { Sequence was colonoscopy followed by EGD } \\
\text { Authors identify a group of FOBT-pos/col-neg patients but do not } \\
\text { report separate outcomes for this subgroup }\end{array}$ & Guaiac & Not reported & 146 \\
\hline
\end{tabular}

EGD Esophagogastroduodenoscopy

This represents $1 \%$ or less of the total population studied. The final two studies $(19,21)$ did not provide outcome information that could be specifically related to the FOBT-positive/ colonoscopy-negative subgroup. Therefore, no conclusion can be drawn regarding the UGI cancer yield in these studies.

\section{Probable UGI contributors to a positive FOBT}

Five studies reported outcomes other than UGI cancer outcomes (Table 2). Based on expert opinion, the panel divided these other noncancer outcomes into two groups: probable UGI contributors to a positive FOBT and probable UGI incidental finding. Probable UGI contributors include peptic ulcer disease (stomach, esophagus and duodenum), esophagitis, vascular malformations and large gastric polyps (larger than $1 \mathrm{~cm}$ in size). One study of symptomatic patients (14) reported no probable contributors. Among other symptomatic patients (including those with severe anemia), $11 \%$ to $21 \%$ had a probable UGI contributor to a positive FOBT (16), whereas $7 \%$ to $19 \%$ of asymptomatic patients had a probable contributor (15-17). The Hisamuddin et al (20) study involved both asymptomatic and symptomatic patients, and reported that $16 \%$ of this aggregate group had a probable contributor. 
TABLE 2

Upper gastrointestinal (UGI) outcomes in fecal occult blood test (FOBT)-positive/colonoscopy-negative patients who underwent esophagogastroduodenoscopy (EGD)

\begin{tabular}{|c|c|c|c|c|c|c|c|}
\hline Author (reference) & $\begin{array}{c}\text { Study } \\
\text { type }\end{array}$ & Group(s) & $\mathbf{n}$ & EGD-positive & UGI cancer* & 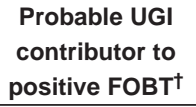 & $\begin{array}{c}\text { Probable UGI } \\
\text { incidental } \\
\text { finding }{ }^{\ddagger}\end{array}$ \\
\hline Thomas and Hardcastle (14) & $P$ & Symptomatic & 14 & $6(43)$ & $1(7)$ & $0(0)$ & $5(36)$ \\
\hline Hsia and al-Kawas (15) & $P$ & Asymptomatic & 70 & $19(27)$ & $0(0)$ & $13(19)^{\S}$ & $7(10)^{\S}$ \\
\hline \multirow[t]{5}{*}{ Chen et al (16) } & $\mathrm{R}$ & Asymptomatic & 117 & $50(43)$ & $0(0)$ & $8(7)$ & $42(36)$ \\
\hline & & Symptomatic & 37 & $13(35)$ & $0(0)$ & $4(11)$ & $9(24)$ \\
\hline & & Severely anemic & 33 & $15(45)$ & $0(0)$ & $7(21)$ & $8(24)$ \\
\hline & & Incomplete (unknown) & 24 & $10(42)$ & $0(0)$ & $5(21)$ & $5(21)$ \\
\hline & & Total & 211 & $88(42)$ & $0(0)$ & $24(11)$ & $64(30)$ \\
\hline Bini et al (17) & $\mathrm{R}$ & Asymptomatic & 498 & $141(28)$ & $5(1)$ & $66(13)$ & $70(14)$ \\
\hline Zappa et al (7) & $\mathrm{R}$ & Unknown & 3555 & NA & $14(<1)^{\star \star}$ & NR & NR \\
\hline Hisamuddin et al (20) & $\mathrm{R}$ & Asymptomatic and symptomatic & 70 & $25(36)$ & $0(0)$ & $11(16)$ & $14(20)$ \\
\hline Zuckerman and Benitez (18) & $P$ & Asymptomatic and symptomatic & 74 & $27(36)$ & $1(1)$ & NR & NR \\
\hline Ali et al (19) & $\mathrm{R}$ & Unknown & 125 & $16(13)$ & NR & NR & NR \\
\hline Stray and Weberg (21) & $\mathrm{P}$ & Unknown & 146 & $37(25)$ & NR & NR & NR \\
\hline
\end{tabular}

Data presented as $n$ (\%), unless indicated otherwise. *Includes gastric and esophageal cancers; ${ }^{\dagger}$ Includes peptic ulcer disease, esophagitis, vascular malformations and gastric polyps (>1 cm); ${ }^{\ddagger}$ Includes Barrett's esophagus, gastric and duodenal erosions, gastritis, duodenitis, jejunitis, esophageal and gastric varices, esophageal stricture, duodenal adenoma, nonerosive esophagitis, benign gastroduodenal disease and small gastric polyps (<1 cm); ${ }^{\S}$ These numbers add to 20 instead of 19 because one patient had both a probable contributor to their positive FOBT and a probable incidental finding; "EGD not performed, patients followed through registries and databases; **UGI cancers occurring within 35 months of positive FOBT. NA Not applicable; NR Not reported; P Prospective; R Retrospective

None of the remaining four studies $(7,18,19,21)$ reported on noncancer outcomes separately for their FOBT-positive/ colonoscopy-negative subgroups.

\section{Probable UGI incidental findings}

Probable UGI incidental findings were defined by the panel as lesions not likely to contribute to a positive FOBT. These include Barrett's esophagus, gastric and duodenal erosions, duodenitis, jejunitis, esophageal and gastric varices, esophageal stricture, duodenal adenoma, nonerosive esophagitis, benign gastroduodenal disease and small gastric polyps (less than $1 \mathrm{~cm}$ in size). Among symptomatic patients (including those with severe anemia in one study), $24 \%$ to $36 \%$ had a probable UGI incidental finding at EGD $(14,16)$, while $10 \%$ to $36 \%$ of asymptomatic patients had a probable incidental finding (15-17). Hisamuddin et al (20) had both asymptomatic and symptomatic patients in their study and reported that $20 \%$ of this aggregate group had a probable incidental finding.

None of the other four studies $(7,18,19,21)$ reported on noncancerous outcomes separately for their FOBT-positive/ colonoscopy-negative subgroups.

\section{Effect of anemia}

There were few data from these studies relating to anemia as a possible predictor of EGD results (in addition to positive FOBT and negative colonoscopy). Furthermore, the outcomes reported differ among studies and could not be combined.

Effect of nonsteroidal anti-inflammatory drug use

There were few data from these studies relating to the investigation of acetylsalicylic acid or nonsteroidal anti-inflammatory drug (NSAID) use as a possible predictor of EGD results (in addition to positive FOBT and negative colonoscopy). Furthermore, the outcomes reported differed among studies and could not be combined.

\section{Development of recommendations; internal and external} review

Once the data were collected and collated, the panel reconvened to formulate the guideline recommendation(s) based on the available evidence. At this point, the document was sent for internal review followed by external review as described in the Methods section.

All feedback received through the internal and external review process was discussed by the panel and changes to the document were made, where appropriate. The main comment made by several reviewers was that a $1 \%$ yield for the detection of UGI malignancy may make it worth performing EGD given that the detection rate of CRC in CRC screening programs would be similar. The panel believed that this warranted comment and, consequently, a revision to the Discussion section was made.

\section{DISCUSSION}

The current management of patients who undergo screening for CRC and test FOBT positive and colonoscopy negative is inconsistent. As a greater proportion of the population complies with guidelines for CRC screening, there will be an increasing and perhaps substantial number of such patients who fall into this category. However, there are relatively few studies that used sound study design and appropriate outcome assessment to fully address whether EGD is warranted in this situation. The evidence base compiled for the present document consists of four prospective and five retrospective studies. Two of these studies $(19,21)$ only identified a group of FOBT-positive/colonoscopynegative patients with a positive EGD, but provided no information regarding the endoscopic findings, making the results uninterpretable. The current document does not address the entire issue of how to manage FOBT-positive/colonoscopynegative patients, but examines whether EGD is warranted to detect UGI cancer in this group of patients. 
In the remaining seven studies, the prevalence of UGI cancer was very low. Three studies $(15,16,20)$ found no UGI cancers. Three studies $(7,17,18)$ observed UGI cancer rates of $1 \%$ or lower, and one study (14) noted a UGI cancer rate of $7 \%$, representing one case out of 14 symptomatic patients. It should be noted that while a $1 \%$ yield of UGI cancer may seem comparable to the yield of colon cancers detected at screening colonoscopy using FOBT, the quality of the available studies evaluating EGD in FOBT-positive/colonoscopy-negative patients are not as scientifically rigorous as those evaluating the use of FOBT in CRC screening. The gastroscopy studies contain heterogeneous samples that are not truly representative of a screening population and the number of patients evaluated is smaller than that used in the landmark CRC screening studies that established the benefit of FOBT.

Diagnostic findings at EGD other than UGI cancer were more prevalent. Overall, a probable UGI contributor to the positive FOBT was reported in $7 \%$ to $21 \%$ of FOBT-positive/ colonoscopy-negative patients. Probable contributors were reported to be peptic ulcer disease, esophagitis, vascular malformations and gastric polyps (greater than $1 \mathrm{~cm}$ in size). It is not known if gastric polyps greater than $1 \mathrm{~cm}$ in size cause a positive FOBT. These larger gastric polyps were only reported in two studies $(17,20)$, and their inclusion as a probable UGI contributor to a positive FOBT did not change any conclusions of the present report. The proportion of cases with findings that were reported as likely to be incidental (and unlikely to account for a positive FOBT) occurred in $10 \%$ to $36 \%$ of patients. These incidental findings included Barrett's esophagus, gastric and duodenal erosions, gastritis, duodenitis, jejunitis, esophageal and gastric varices, esophageal stricture, duodenal adenoma, benign gastroduodenal disease and gastric polyps. The variability in the descriptions of UGI lesions other than cancer is likely the result of the variations between studies in defining what constitutes a positive EGD.

There were very few data regarding EGD results and the presence or absence of anemia, and even fewer data regarding EGD and NSAID use. Moreover, the papers that did report on these variables all disclosed different outcomes. Because most patients who undergo screening are older than 50 years of age, many will be taking acetylsalicylic acid for cardiovascular disease prevention and/or NSAIDs for arthritis and analgesia. In addition, anemic patients are unique and should be considered symptomatic and, therefore, do not fall under the auspices of screening programs. Anemia is a 'red-flag' sign that requires further investigation. These two groups of patients would benefit from further study as separate subgroups.

The body of literature examining the controversial issue of performing routine EGD in FOBT-positive/colonoscopynegative patients is sparse. The data gathered from the studies in the present systematic review suggest that the number of UGI cancers found in FOBT-positive/colonoscopy-negative patients is small - in the order of $1 \%$ or less - although the rate of other UGI findings was higher. However, although the risk associated with EGD is small (approximately $0.03 \%$ for perforation [22,23]), other factors related to cost and endoscopic resources are significant, considering the large numbers of patients who will emerge from CRC screening programs with a positive FOBT and a negative colonoscopy. Performing routine EGD in these patients would significantly add to the cost of screening programs while potentially adding little value with respect to the effectiveness of screening for UGI cancer.

\section{CONCLUSION}

After examining the available evidence, the panel provided the following recommendation:

The current body of evidence is insufficient to recommend for or against routine EGD as a means of detecting gastric or esophageal cancers for patients who are FOBT-positive/ colonoscopy-negative in a population-based CRC screening program. The decision to perform EGD should be individualized and based on clinical judgement.

The key evidence supporting this recommendation is as follows:

- Four prospective $(14,15,18,21)$ and five retrospective $(7,16,17,19,20)$ studies of patients who were FOBT-positive/ colonoscopy-negative and underwent EGD. Of these, two studies $(19,21)$ reported positive EGD but no information about endoscopic findings, and several studies did not document the presence of anemia, UGI symptoms or the use of NSAIDs.

- Based on this limited evidence, EGD had a low yield for UGI cancer, generally $1 \%$ or less, even in symptomatic or severely anemic patients. The yield for detecting nonmalignant findings potentially contributing to a positive FOBT was $11 \%$ to $21 \%$, while the yield for incidental findings unlikely contributing to a positive FOBT was $10 \%$ to $36 \%$. There were very few data regarding EGD results in the context of anemia or NSAID use.

A recommendation regarding the use of EGD for the detection of noncancerous pathology is not provided because it is beyond the scope of the present review.

Furthermore, adequately powered studies are needed to investigate the incidence of gastric or esophageal cancer in patients enrolled in a population-based CRC screening program who are FOBT positive and colonoscopy negative.

CONFLICTS OF INTEREST: All authors declare no conflicts of interest.

\section{APPENDIX 1}

\section{MEDLINE search strategy}

\section{Search 1}

1. Colorectal neoplasms/di

2. exp Colonoscopyl

3. 1 or 2

4. Digestive System Diseases/di

5. Gastrointestinal neoplasms/di

6. Gastrointestinal diseases/di

7. Stomach ulcer/di

8. Stomach neoplasms/di

9. Peptic ulcer/di

10. Peptic ulcer hemorrhage/di

11. Liver disease/di

12. or/4-11

13. exp Mass Screening/

14. 3 and 12 and 13

15. limit 18 to english language

16. limit 19 to $\mathrm{yr}=$ "1990-2008" 


\section{Search 2}

1. exp Gastroscopy/

2. Esophagogastroduodenoscopy.mp.

3. exp Endoscopy/ or exp Endoscopy, Gastrointestinal/ or exp Endoscopy, Digestive System/

4. 1 or 2 or 3

5. Gastrointestinal neoplasms/di

6. Gastrointestinal diseases/di

7. Stomach ulcer/di

8. Stomach neoplasms/di

9. peptic ulcer/di

10. peptic ulcer hemorrhage/di

11. Liver diseases/di

12. or/5-11

13. exp Mass Screening/

14. 4 and 12 and 13

15. limit 14 to english language

16. limit 15 to $\mathrm{yr}=$ "1990-2008"

\section{Search 3}

1. exp Gastroscopy/

2. Esophagogastroduodenoscopy.mp. or exp Endoscopy, Digestive System/

3. 1 or 2

4. $\exp$ Gastrointestinal Neoplasms/

5. exp Gastrointestinal Diseases/

6. exp Stomach Ulcer/

7. exp Stomach Neoplasms/

8. $\exp$ Peptic Ulcer/

9. exp Peptic Ulcer Hemorrhage/

10. Liver disease/di

11. or/4-10

12. exp Mass Screening/

13. 3 and 11 and 12

14. exp Colorectal Neoplasms/

15. 13 not 14

16. limit 15 to english language

17. limit 16 to $\mathrm{yr}=$ "1990-2008"

\section{APPENDIX 2}

\section{EMBASE search strategy}

Search 1

1. Colorectal cancer/di

2. exp COLONOSCOPY/

3. exp Cancer Screening/

4. exp Occult Blood/

5. $\exp$ GASTROSCOPY/

6. $\exp$ ESOPHAGOGASTRODUODENOSCOPY/

7. exp Gastrointestinal Endoscopy/

8. Digestive system cancer/di

9. Stomach ulcer/di

10. Stomach cancer/d

11. Upper gastrointestinal bleeding/di

12. Esophagus cancer/di

13. Peptic ulcer/di

14. Liver disease/di

15. or/5-14

16. 1 and 2 and 3 and 4 and 15

17. limit 16 to english language

18. limit 17 to $\mathrm{yr}=$ "1990-2008"

\section{Search 2}

1. Colorectal cancer/di

2. exp COLONOSCOPY/

3. 1 or 2
4. Digestive System Cancer/di

5. gastrointestinal disease/di

6. stomach ulcer/di

7. stomach cancer/di

8. upper gastrointestinal bleeding/di

9. esophagus cancer/di

10. peptic ulcer/di

11. liver disease/di

12. or/4-11

13. 3 and 12

14. limit 13 to english language

15. limit 14 to $\mathrm{yr}=$ "1990-2008"

Search 3

1. $\exp$ GASTROSCOPYI

2. $\exp$ ESOPHAGOGASTRODUODENOSCOPYI

3. $\exp$ Gastrointestinal Endoscopy/

4. 1 or 2 or 3

5. Digestive System Cancer/d

6. Gastrointestinal disease/di

7. stomach ulcer/di

8. stomach cancer/di

9. Upper gastrointestinal bleeding/di

10. Esophagus cancer/di

11. Peptic ulcer/di

12. Liver disease/di

13. or/5-12

14. exp Mass Screening/

15. exp Cancer Screening/

16. 14 or 15

17. 4 and 13 and 16

18. limit 17 to english language

19. limit 18 to $\mathrm{yr}=$ "1990-2008"

\section{APPENDIX 3}

Environmental scan (National Guideline Clearinghouse)

International guideline developers:

National Institute for Health Excellence (NICE) (United Kingdom [UK]) NICE guidance

The Scottish Intercollegiate Guidelines Network (SIGN) (UK) - SIGN guidelines American Society of Clinical Oncology (ASCO) (United States) - ASCO guidelines

National Comprehensive Cancer Network (NCCN) (United States) - NCCN home (consensus based)

National Health and Medical Research Council (Australia) - Cancer guidelines New Zealand Guidelines Group - Guidelines

Canadian provincial cancer agencies:

BC Cancer Agency - Cancer management guidelines

Alberta Cancer Board - Treatment guidelines

Saskatchewan Cancer Agency - Follow-up guidelines

Cancer Care Manitoba (CCM) - CCM home

Cancer Care Nova Scotia - Guidelines

National cancer agencies (UK, Australia, New Zealand):

New Zealand Cancer Control Trust

The Cancer Council Australia

National Cancer Control Initiative (Australia)

The Collaboration for Cancer Outcomes Research and Evaluation (Australia)

State Government of Victoria, Australia

Peter MacCallum Cancer Centre (Australia)

Medical Oncology Group of Australia

Cancer UK 
Cancer Services Collaborative, Avon Somerset and Wiltshire (UK)

National Health Service (UK)

Organizations (project specific):

Canadian Association of Gastroenterology

Ontario Association of Gastroenterology

Canadian Digestive Health Foundation

American Gastroenterology Association

British Society of Gastroenterology

United European Gastroenterology Foundation

European Society for Primary Care Gastroenterology

American Society of Gastrointestinal Endoscopy

American College of Gastroenterology

Conferences:

Community Oncology Conference

\section{REFERENCES}

1. Canadian Cancer Society, National Cancer Institute of Canada. Canadian cancer statistics 2008. Toronto, Canada, Canadian Cancer Society; 2008.

2. O'Connell JB, Maggard MA, Ko CY. Colon cancer survival rates with the new American joint committee on cancer sixth edition staging. J Natl Cancer Inst 2004;96:1420-5.

3. Kewenter J, Brevinge H, Engaras B, Haglind E, Ahren C. Results of screening, rescreening, and follow-up in a prospective randomized study for detection of colorectal cancer by fecal occult blood testing. Results for 68,308 subjects. Scand J Gastroenterol 1994;29:468-73.

4. Mandel JS, Church TR, Ederer F, Bond JH. Colorectal cancer mortality: Effectiveness of biennial screening for fecal occult blood. J Natl Cancer Inst 1999;91:434-7.

5. Scholefield JH, Moss S, Sufi F, Mangham CM, Hardcastle JD. Effect of faecal occult blood screening on mortality from colorectal cancer: Results from a randomised controlled trial. Gut 2002;50:840-4.

6. Kronborg O, Jorgensen OD, Fenger C, Rasmussen M. Randomized study of biennial screening with a faecal occult blood test: Results after nine screening rounds. Scand J Gastroenterol 2004;39:846-51.

7. Zappa M, Visioli CB, Ciatto S, et al. Gastric cancer after positive screening faecal occult blood testing and negative assessment. Dig Liver Dis 2007;39:321-6.

8. UK Colorectal Cancer Screening Pilot Group. Results of the first round of a demonstration pilot of screening for colorectal cancer in the United Kingdom. BMJ 2004;329:133.

9. Manfredi S, Piette C, Durand G, Plihon G, Mallard G, Bretagne JF. Colonoscopy results of a French regional FOBT-based colorectal cancer screening program with high compliance. Endoscopy 2008;40:422-7.

10. Bressler B, Paszat LF, Chen Z, Rothwell DM, Vinden C, Rabeneck L. Rates of new or missed colorectal cancers after colonoscopy and their risk factors: A population-based analysis. Gastroenterology 2007;132:96-102.

11. Browman GP, Levine MN, Mohide EA, et al. The practice guidelines development cycle: A conceptual tool for practice guidelines development and implementation. J Clin Oncol 1995;13:502-12.

12. Chen TH, Yen MF, Lai MS, et al. Evaluation of a selective screening for colorectal carcinoma: The Taiwan Multicenter Cancer Screening (TAMCAS) project. Cancer 1999;86:1116-28.

13. Jouve JL, Remontet L, Dancourt V, et al. Estimation of screening test (Hemoccult) sensitivity in colorectal cancer mass screening. Br J Cancer 2001;84:1477-81.

14. Thomas WM, Hardcastle JD. Role of upper gastrointestinal investigations in a screening study for colorectal neoplasia. Gut 1990;31:1294-7.

15. Hsia PC, al-Kawas FH. Yield of upper endoscopy in the evaluation of asymptomatic patients with Hemoccult-positive stool after a negative colonoscopy. Am J Gastroenterol 1992;87:1571-4.

16. Chen YK, Gladden DR, Kestenbaum DJ, Collen MJ. Is there a role for upper gastrointestinal endoscopy in the evaluation of patients with occult blood-positive stool and negative colonoscopy? Am J Gastroenterol 1993;88:2026-9.

17. Bini EJ, Rajapaksa RC, Valdes MT, Weinshel EH. Is upper gastrointestinal endoscopy indicated in asymptomatic patients with a positive fecal occult blood test and negative colonoscopy? Am J Med 1999;106:613-8.

18. Zuckerman G, Benitez J. A prospective study of bidirectional endoscopy (colonoscopy and upper endoscopy) in the evaluation of patients with occult gastrointestinal bleeding. Am J Gastroenterol 1992;87:62-6.

19. Ali M, Yaqub M, Haider Z, Anees I, Bhargava S, Gian J. Yield of dual endoscopy for positive fecal occult blood test. Am J Gastroenterol 2003;98:82-5.

20. Hisamuddin K, Mowat NAG, Phull PS. Endoscopic findings in the upper gastrointestinal tract of faecal occult blood-positive, colonoscopy-negative patients. Dig Liver Dis 2006;38:503-7.

21. Stray N, Weberg R. A prospective study of same day bi-directional endoscopy in the evaluation of patients with occult gastrointestinal bleeding. Scand J Gastroenterol 2006;41:844-50

22. Silvis SE, Nebel O, Rogers G, Sugawa C, Mandelstam P. Endoscopic complications. Results of the 1974 American society for gastrointestinal endoscopy survey. JAMA 1976;235:928-30.

23. Bhatia NL, Collins JM, Nguyen CC, Jaroszewski DE, Vikram HR, Charles JC. Esophageal perforation as a complication of esophagogastroduodenoscopy. J Hosp Med 2008;3:256-62. 


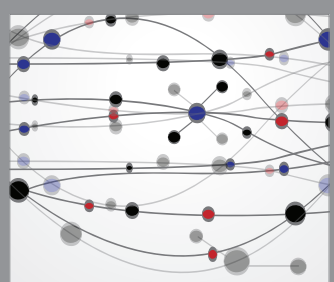

The Scientific World Journal
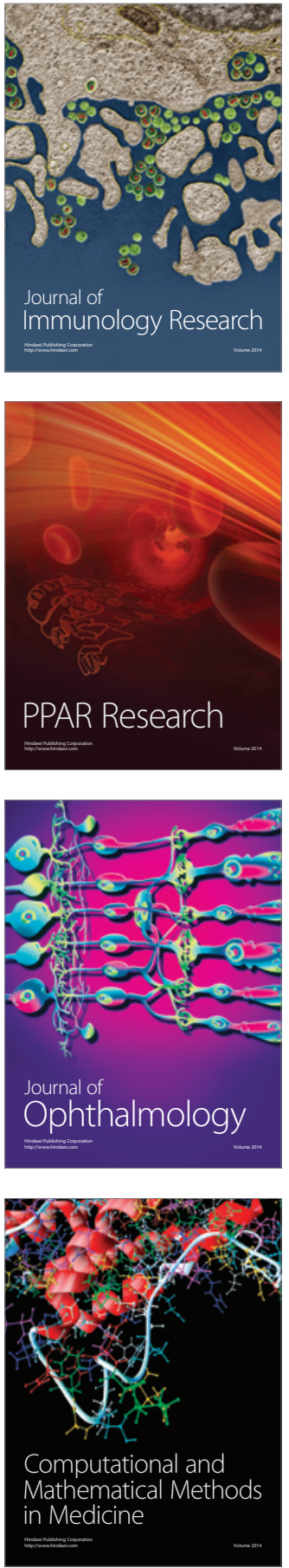

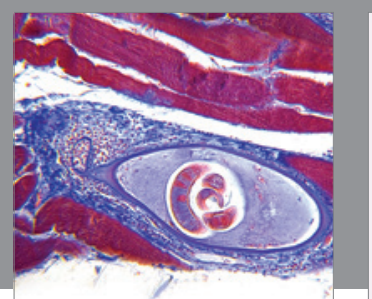

Gastroenterology Research and Practice

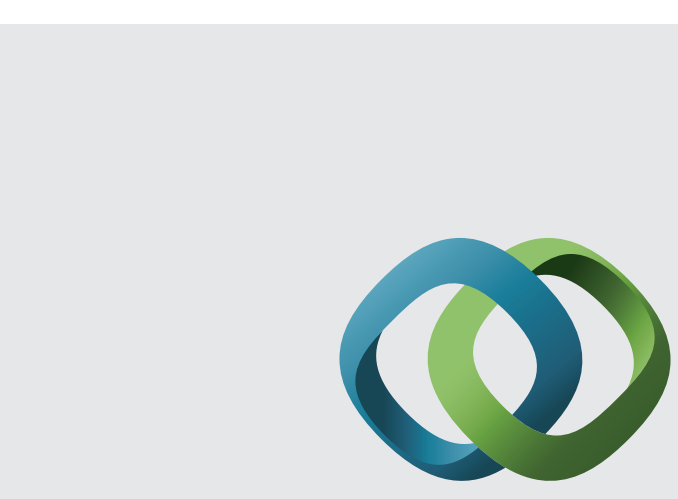

\section{Hindawi}

Submit your manuscripts at

http://www.hindawi.com
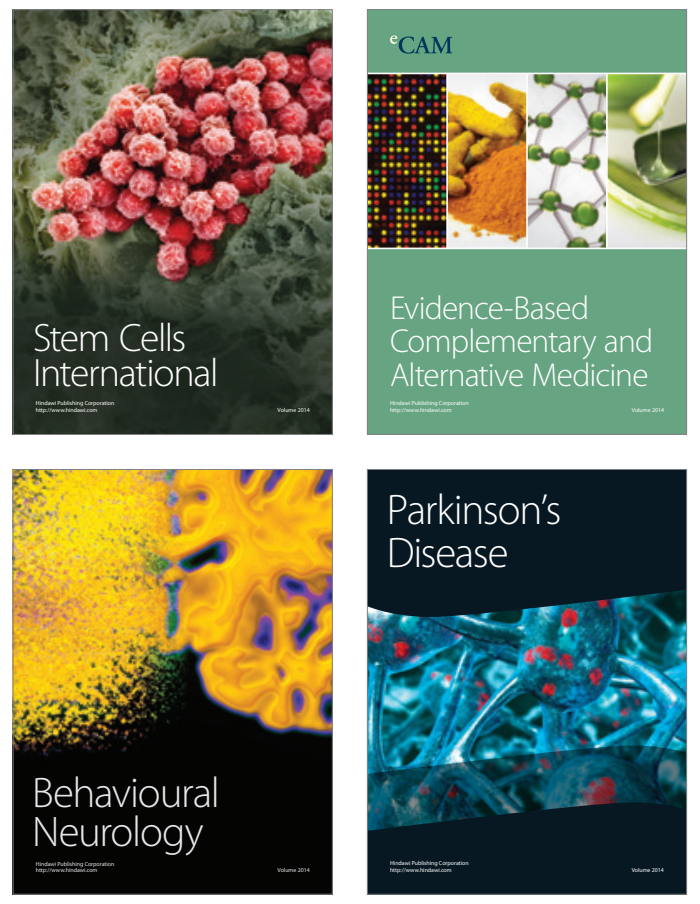
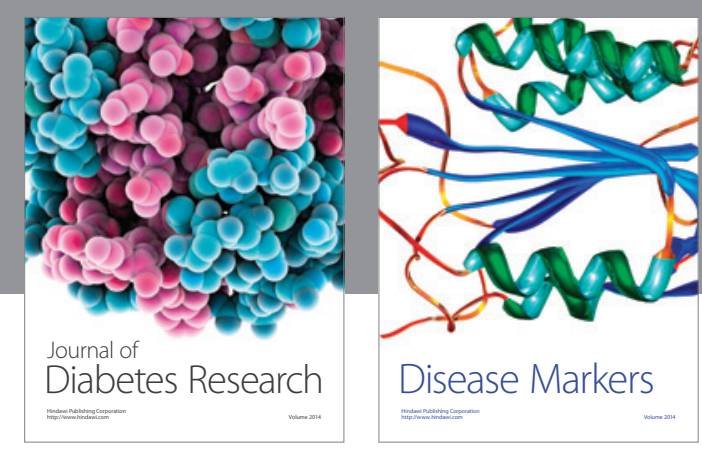

Disease Markers
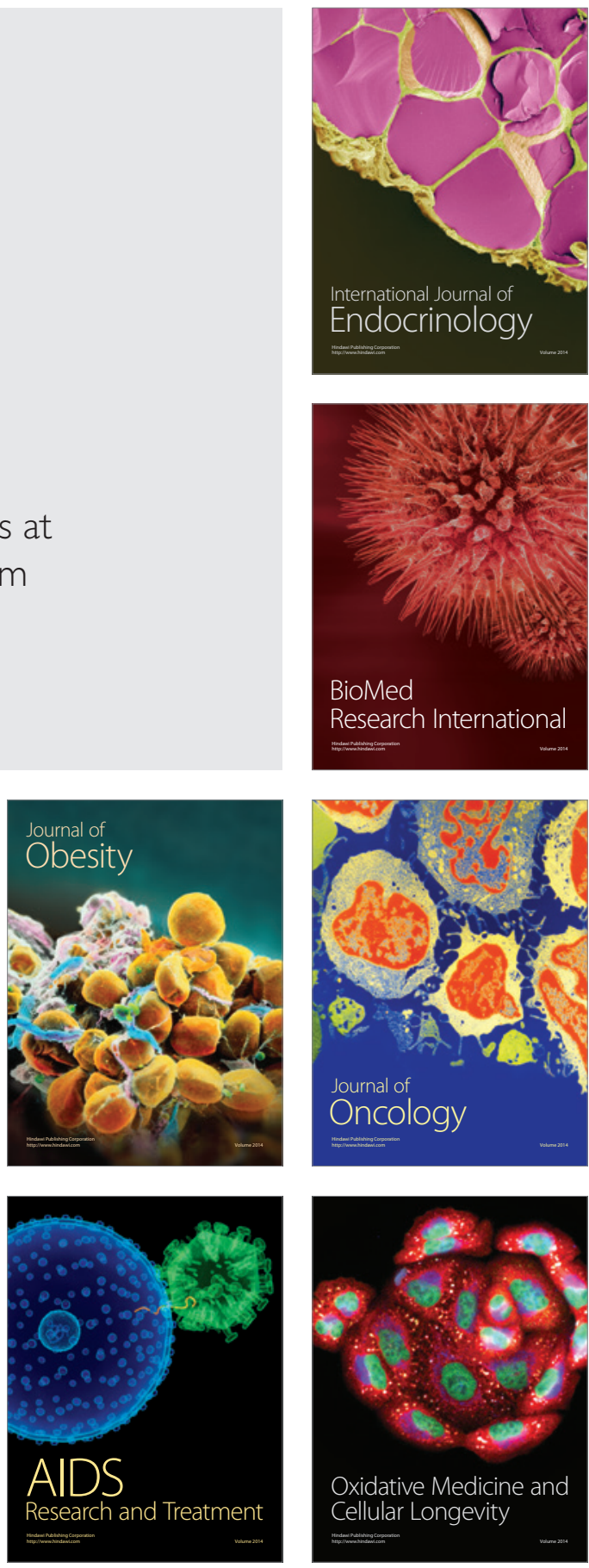